\title{
THE EDUCATOR'S PERSPECTIVE: KNOWLEDGE, ATTITUDE AND PRACTICES ON OCCUPATIONAL SAFETY AND HEALTH AT SCHOOL AMONG PRIMARY AND SECONDARY SCHOOL TEACHERS
}

\author{
Nursyuhada Binti Mohamad Yusoff ${ }^{1}$, Vivien How ${ }^{1 *}$, Ezza Sabrina Binti Azmi ${ }^{1}$ and Khairuddin Bin Othman ${ }^{2}$ \\ ${ }^{1}$ Department of Environmental and Occupational Health, Faculty of Medicine and Health Sciences, \\ Universiti Putra Malaysia \\ ${ }^{2}$ Department of Community Support and Services, Malaysian First Aid Society, Selangor, Malaysia
}

${ }^{*}$ Corresponding author: Vivien How

Email: vivien@upm.edu.my

\begin{abstract}
Introduction: School can be considered as a relatively moderate risk working environment due to the various hazards assembled in the school. Nevertheless, Occupational Safety and Health (OSH) training is yet to formally inclusive into teachers' training module, and the current one-off or ad-hoc OSH training mainly targeted among school students. The different $\mathrm{OSH}$ awareness exists among teacher and student have hinder the provision of sustainable and effective safety and health training program at school levels. Objective: To assess the knowledge, attitude and practice among primary and secondary school teachers towards OSH at the school environment. Method: A cross-sectional survey carried out at three (3) primary schools and three (3) secondary schools after stratified random sampling. School teachers from these schools were randomly selected among those who had at least one year work experience as permanent teacher at the current school through the fishbowl technique. A structured questionnaire was used and total 136 teachers were assessed on their knowledge, attitude and practices on OSH at schools. Result: Study found that primary and secondary school teachers have different knowledge, attitude and practices of OSH at school levels. Overall, the knowledge level of secondary school teacher (62.1\% of high to medium knowledge levels) are higher than the primary school teachers (41.1\% of high to medium knowledge levels); at the same time, 93.1\% of secondary school teachers show positive attitude while $88.5 \%$ of primary school teachers show positive attitude on safety and health at schools. In general, OSH practice level among the primary (88.5\%) and secondary school teachers (86.2\%) are at relatively good levels. Besides, there is positive association with knowledge and attitude on OSH behavior among primary school teachers. Apart of this, there is positive but relatively weak association with knowledge and practices and knowledge and attitudes among primary and secondary school teachers. Conclusion: Considering the background differences between primary and secondary school teachers, a sustainable OSH learning mechanism should be planned and designed together with OSH practitioners and Ministry of Education to achieve a sustainable safety and healthy sound school environment for teacher to work and for students to learn.
\end{abstract}

Keyword: School Health, School Safety, Teacher, Knowledge, Attitude, Practices

\section{INTRODUCTION}

School can be considered as a relatively moderate risk working environment due to the various hazards assembled in the school, which includes, safety hazards, (biological, physical, chemical, ergonomic and psychological) health hazards and environmental hazards. Even though occasional reports of injuries at school are seen in the dailies, there is a dearth data at present on injuries at school. ${ }^{1}$ It is difficult to track down cases because there are no official communication portal to report accidents or near misses that occurs in school. ${ }^{2}$ To date, Occupational Safety and Health (OSH) training is yet to formally inclusive into teachers' training module, and the current one-off or ad-hoc OSH training mainly targeted among school students only. The different OSH awareness exists among both teachers and students hindered the provision of sustainable and an effective safety and health training program at the school levels. In fact, study has shown that one of the most effective approach to reduce injuries to young workers in the working industry is to improve the provision of sustainable and effective safety and health training program among educator and learner at school levels. ${ }^{3}$

Recently, ASEAN has initiated a working group named "ASEAN Safe School Initiative (ASSI)". Nevertheless, the aims of this working together is particularly making children in schools and communities resilient to disasters, mainly focusing on emergency response, first aid and health-related issues. Apart from disaster resilience, school environment should also be considered as a workplace as listed under Occupational Safety and Health Act (OSHA) 1994. Nonetheless, the existing OSH practices only concerned among the working population at industrial settings. An important concept in OSHA 1994 is self-regulation states that the responsibility for managing safety and health lies with those who create the risks and those who work with the risks. Nevertheless, our school 
educators, staffs and students who spent most of their time at this work environment do not aware that practising the OSH management in the school environment falls under their responsibility.

Teachers are considered as role models to transmit values of life. Primary (elementary) teachers have a unique opportunity to make a positive impact on children as they guide children who are just discovering the thrill of enjoy reading, writing, math, language, art and basic sciences. However, secondary (high) school teachers are usually masters of the subjects (art, science or languages) they teach, at the same time, helping students reach their full academic potential and start thinking about their futures beyond high school. ${ }^{4}$ Anyhow, school teachers by virtue of their training can influence a large number of children thereby play a major role in the planning and implementation of OSH practices at the school level. Since they play a very important role in educating and creating a safe and healthy school environment to the students, teachers needed to be able to identify the OSH hazards and response or mitigate the OSH risks proactively. ${ }^{5}$

This study was undertaken with the objective of assessing the knowledge, attitude and practice among both primary and secondary school teachers towards $\mathrm{OSH}$ at the school environment.

\section{METHODS}

This was a cross-sectional survey carried out at three (3) primary schools and three (3) secondary schools after stratified random sampling. School teachers from these schools were randomly selected among those who had at least one year work experience as permanent teacher at the current school through the fishbowl technique. A self-administered questionnaire was developed and total 136 teachers were assessed on their knowledge, attitude and practices on $\mathrm{OSH}$ at schools.

Table 1: Background Information of School Teachers $(\mathrm{N}=136)$

\begin{tabular}{llcc}
\hline Background Information, $\mathbf{n}(\%)$ & $\begin{array}{c}\text { Primary School } \\
\text { Teacher }(\mathbf{n = 7 8})\end{array}$ & $\begin{array}{c}\text { Secondary School } \\
\text { Teacher }(\mathbf{n = 5 8})\end{array}$ \\
\hline Gender & Male & $17(21.8)$ & $7(12.1)$ \\
Age (year) & Female & $61(78.2)$ & $51(87.9)$ \\
& $\leq 39$ & $44(56.2)$ & $25(43.1)$ \\
& $40-49$ & $19(24.4)$ & $19(32.8)$ \\
Service Duration & $\geq 50$ & $15(19.2)$ & $14(24.1)$ \\
(year) & $\leq 14$ & $46(59.0)$ & $27(46.6)$ \\
& $15-19$ & $8(10.3)$ & $14(24.1)$ \\
Attended & $20-24$ & $11(14.1)$ & $4(6.9)$ \\
Training & $\geq 25$ & $13(16.7)$ & $13(22.4)$ \\
& Safety and Health & $18(23.1)$ & $25(43.1)$ \\
& First Aid & $32(41.0)$ & $30(51.7)$ \\
& Emergency Response & $21(26.9)$ & $32(55.2)$ \\
\hline
\end{tabular}

The questionnaire consists of four (4) sections, (a) Socio-demographic characteristics (12 items), (b) Knowledge on safety and health at school (15 items), (c) Attitude towards safety and health issues (15 items), (d) Safety and health practices at school levels (15 items). The questionnaire was tested on validity and reliability to ensure that the question items are getting measures as accordance to the study objectives. Content validity was performed by letting recognized subject matters OSH experts to evaluate whether test items assess define the content of the study. A content validity ratio of 0.8 indicate that at least half of the subject matters OSH expects rated the items as essential. Next, test-retest reliability was conducted among 15 school teachers who met the similar inclusive criteria as The same structured questionnaire was given twice to 15 school teachers at one-week interval. A test-retest reliability coefficient shows that most of the test items achieved $0.85-0.65$.

Participants were asked to respond to each item according to the response format provided at the questionnaire. Researcher was always available during questionnaire answering session, and the participants were encouraged to approach her whenever they needed clarification of any point. An estimated of 15-20 minutes were recorded for participants to complete all questionnaire items. Descriptive statistics and univariate analysis were performed by using SPSS version 24.0.

\section{RESULTS}

In the present study, total of 136 teachers were participated in this study. There are more female than male teachers in services and most of them are at the age of $\leq 39$ - 49-year-old. Some of the participants claimed that they attended safety and health-related training (Table 1). the 136 teachers who participate in this study. 
Knowledge on OSH at School among School Teachers

Assessment of participants' OSH knowledge in schools included items on knowledge of biological, physical, chemical, ergonomic and safety hazards and emergency response at the school environment. Table 2 found that $50.0 \%$ of the respondents obtained a low level of knowledge, $41.9 \%$ had medium knowledge and the rest $8.1 \%$ with high level. From those results, $59.0 \%$ of the primary school teachers had low level of knowledge, $38.5 \%$ with medium knowledge and another $2.6 \%$ with high knowledge. As for the secondary school teachers, result stated that there were $37.9 \%$ with low level of knowledge, $46.6 \%$ at medium knowledge and $15.5 \%$ with high knowledge level. Overall, there is significant different of knowledge on OSH at school among primary and secondary school teachers.

Table 2: Levels of Knowledge among School Teachers ( $\mathrm{N}=136)$

\begin{tabular}{llrr}
\hline & & \multicolumn{1}{c}{$\begin{array}{c}\text { Primary School } \\
\text { Teacher }(\mathbf{n = 7 8})\end{array}$} & \multicolumn{1}{c}{$\begin{array}{c}\text { Secondary School } \\
\text { Teacher }(\mathbf{n = 5 8})\end{array}$} \\
\hline Knowledge levels, $\mathbf{n}(\%)$ & Low & $46(59.0)$ & $22(37.9)$ \\
& Medium & $30(38.5)$ & $27(46.6)$ \\
& High & $2(2.6)$ & $9(15.5)$ \\
Median $(I Q R)^{\text {a }}$ & & $8.00(1.0)$ & $12.0(2.25)$ \\
$Z_{\text {Statistics }}$ & & -3.036 & \\
- $^{\text {-value }}$ & & $0.002^{*}$ & \\
\hline
\end{tabular}

${ }^{a}$ Mann-Whitney U-test, ${ }^{*} p$-value is significant at 0.05 level

Attitude on OSH at School among School Teachers

Assessment of participants' OSH attitude aimed to evaluate the perception of teachers on OSH at the school environment. Table 3 reports that a majority of $90.4 \%$ of teachers having a positive level of attitude on OSH at school followed by $5.9 \%$ having normal attitude and $3.7 \%$ of them getting negative attitude on OSH at school. This study showed that for primary school teachers $1.3 \%$ got negative level of attitude, $10.3 \%$ scored normal and the majority of $88.5 \%$ with positive level of attitude on OSH at school. As for the secondary school result found that, $6.9 \%$ scored negative attitude level with the rest of $90.4 \%$ as positive attitude. Overall, there is significant different of attitude on $\mathrm{OSH}$ at school among primary and secondary school teachers.

Table 3: Levels of Attitudes among School Teachers ( $N=136)$

\begin{tabular}{|c|c|c|c|}
\hline & & $\begin{array}{l}\text { Primary School } \\
\text { Teacher }(n=78)\end{array}$ & $\begin{array}{l}\text { Secondary School } \\
\text { Teacher }(n=58)\end{array}$ \\
\hline \multirow[t]{2}{*}{ Attitude levels, n(\%) } & Negative & $9(11.5)$ & $4(6.9)$ \\
\hline & Positive & $69(88.5)$ & $54(93.1)$ \\
\hline Median (IQR) ${ }^{a}$ & & $57.50(8.00)$ & $62.50(7.00)$ \\
\hline Z Statistics & & \multicolumn{2}{|c|}{-02.436} \\
\hline$p$-value & & \multicolumn{2}{|c|}{$0.015^{*}$} \\
\hline
\end{tabular}

${ }^{a}$ Mann-Whitney U-test, * $p$-value is significant at 0.05 level

Practices on OSH at School among School Teachers

Items that assessed participants' OSH practices included the preparedness and mitigation measures on $\mathrm{OSH}$ hazards and the response procedures to $\mathrm{OSH}$ risks. Table 4 shows the practice level of school teachers of which $12.5 \%$ of them having poor practice level and the other $87.5 \%$ having good practice of OSH at school.
Study stated that $11.5 \%$ of the primary school teachers had poor practice while $88.5 \%$ of them had good practice level. As for the secondary school teachers, $13.8 \%$ had poor practice while the other $86.2 \%$ had good practice level. Overall, there is no significant different of practices of $\mathrm{OSH}$ among primary and secondary school teachers.

Table 4: Levels of Practices among School Teachers $(N=136)$

\begin{tabular}{llrr} 
& & $\begin{array}{r}\text { Primary School } \\
\text { Teacher }(\mathrm{n}=78)\end{array}$ & \multicolumn{2}{c}{$\begin{array}{c}\text { Secondary School } \\
\text { Teacher }(\mathrm{n}=58)\end{array}$} \\
\hline Practices levels, $\mathrm{n}(\%)$ & Poor & $9(11.5)$ & $8(13.8)$ \\
& Good & $69(88.5)$ & $50(86.2)$ \\
Median (IQR) & ${ }^{a}$ & $57.00(9.00)$ & $56.00(12.25)$ \\
$Z$ Statistics & & -0.869 & \\
$p$-value & & 0.385 & \\
\hline
\end{tabular}


Association between Knowledge, Attitude and Practice of OSH at Schools among School Teachers

Table 5 is to examine the association between $\mathrm{OSH}$ knowledge and attitude, and practice at schools among primary and secondary school teachers. Result found that there is positive association between knowledge and attitude on OSH behavior among primary school teachers. Apart of this, there is positive but relatively weak association between knowledge and practices and knowledge and attitudes among primary and secondary school teachers.

Table 5: Association between Knowledge, Attitude and Practice of OSH at Schools among School Teachers $(\mathrm{N}=136)$

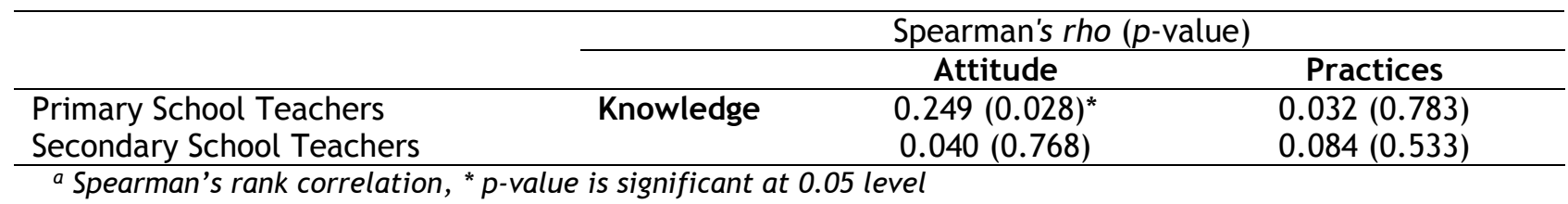

\section{DISCUSSION}

During the school years, our children spend most of their time with their teachers at schools, shaping ways of life and personality development of school children through education system at school level is the key responsibility of school teachers, especially when students follow what teachers do and say. ${ }^{6}$ The knowledge and skills needed to nurture their potentials in taking charge of safety and health sound living and working environment in the future are acquired from their primary to their high school levels. At primary school, teachers manage the class, teach all subjects, and help children develop not only basic competencies, but also emotional and social awareness. While this setting still requires a broad knowledge of many subjects, dealing directly with students' social and emotional development is the core tasks handled by primary school teachers. However, as children progress to high school, learning becomes more about the subject: secondary teachers focus on one or several subjects which they teach to a number of different classes. Their performance will be more strongly evaluated by how well their students perform on these subjects, rather than on how their students develop emotionally and socially. ${ }^{7}$

In spite of these differences between teachers at different education levels, teaching policy is all too often determined by a "one size fits all" approach. While examining the knowledge, attitude and practices of OSH at school among school teachers, this finding also examine exactly in which ways primary and secondary teachers differ across a range of system-level indicators and why it matters, not only for the quality of teaching in the classroom, but also for the attractiveness of teaching as a profession to ensure a safety and healthy sound school environment for themselves and for the school students.
Knowledge on OSH at School among School Teachers

The knowledge level of school teachers found through this study were relatively low among teachers. Past study done in Nigeria also reported teachers to having low knowledge levels on general health knowledge which were presumed to be due to the teachers receiving no special training aside from their professional training on education. ${ }^{8}$ In fact, this study also showed that the secondary school teachers tend to have a higher knowledge levels compared to the primary school teachers since $15.5 \%$ of teachers from secondary school had a high knowledge level in comparison to primary school teachers at $2.6 \%$. This may due to the exposure of primary and secondary school teachers to different educational background, school environment, students and subject taught in school. For instance, past study ${ }^{9}$ reported that knowledge levels on oral hygiene of secondary school teachers were higher compared to the primary school teachers due to different educational background.

\section{Attitude on $\mathrm{OSH}$ at School among School Teachers}

Through this study, it showed that the majority of the school teachers' level of attitude were found to be positive $(90.4 \%)$, for both primary $(88.5 \%)$ and secondary $(93.1 \%)$ schools. This also proved that the secondary school teachers tend to have a higher level of attitude compare to primary school teachers. This may be due to the fact that secondary school teachers are exposed to a more hazardous environment and broader curricular syllabus and subjects compared to primary school teachers. Therefore, secondary school teachers tend to be more aware of their surroundings and the danger around them. A study done in the past stated that a safety culture in an organization are related to attitude, behavior and the environmental factors implemented in order to create and maintain an effective safety and health managements system. ${ }^{10}$ 


\section{Practices on $\mathrm{OSH}$ at School among School Teachers}

In addition, it was also stated that the practices on OSH among school teachers' level were also good $(87.5 \%)$, where primary school teachers' levels $(88.5 \%)$ reported to be higher than the secondary school teachers' (86.2\%). This may be due to the way primary school teacher interacts with their students. Primary students tend to learn and understand better from examples sets by their teachers. The teachers should aware that their actions will be followed by their student thus urging them into practicing more on $\mathrm{OSH}$ matters in order to set a good example.

\section{Association between Knowledge, Attitude, Practice of $\mathrm{OSH}$ at Schools among School Teachers}

Furthermore, results also showed that for the primary school teachers there were a significant association between knowledge and attitude level. This indicates that attitude levels of the teachers do affect their knowledge levels. As for secondary school, it was found that there were a weak association between knowledge and practice levels. This would be the reason that secondary school teachers have higher independency on their teaching routine and school administrative activity, therefore, the OSH practices at school level is mainly due to their willingness to response and mitigate proactively regardless of their knowledge capabilities.

The reason of the different association pattern has led to the understanding that the milestone of implementing $\mathrm{OSH}$ at school levels shall be differed based on teachers from different school levels,

I. The position of primary and secondary school teacher's education in the structure of education systems in Malaysia

II. The academic qualifications of primary and secondary school teacher education

III. The existing Continuing Professional Development (CPD) for teachers to provide them training on the introduction of new educational related policy and regulations.

IV. The different teaching methods and strategies implemented among primary and secondary school teachers

V. The different school administrative environments which either diversify/enlarge or limited the function and programmes of educational establishment at various levels.
Since the role of the school is no longer limited to knowledge delivery, the teacher has now assumed more responsibility to develop his/her students' abilities and interest. ${ }^{11}$ In other words, the education is to meet the demands of our time and of the coming decades, therefore, the school, teaching content and methods of teacher education must be constantly improved. In this situation, a search for new educational strategies and concepts should be undertaken to inclusive $\mathrm{OSH}$ at schools learning among school teachers.

\section{CONCLUSIONS}

Overall, this study found that primary and secondary school teachers have different knowledge, attitude and practices of $\mathrm{OSH}$ at school levels. The knowledge and attitude level of secondary school teacher are higher than the primary school teachers. However, the OSH practice level of the primary school teacher is higher than the secondary school teachers. Besides, there is positive association between knowledge and attitude on OSH behavior among primary school teachers. Apart of this, there is positive but relatively weak association between knowledge and practices and knowledge and attitudes among primary and secondary school teachers.

Findings from this study suggest that educations on OSH at school matters should be given to the educators in order to increase their knowledge level before focusing on education for the students. Considering the differences between teachers at different education levels and school environments, a sustainable $\mathrm{OSH}$ learning mechanism should be planned and designed together with OSH practitioners to achieve a sustainable safety and healthy sound school environment for teacher to work and for students to learn. One of the recommended approaches is to integrate $\mathrm{OSH}$ training into teacher's professional training module through with the active participation by both OSH professional and Ministry of Education, instead of having a one-off or any ad-hoc safety and health training at school level. It shall initiate by first turning the implementation of the knowledge and attitude on $\mathrm{OSH}$ into practices by prioritizing safety and health facility settings at school.

\section{ACKNOWLEDGEMENTS}

This manuscript was prepared for Special Topics in Family Health course as part of requirement for the degree of Doctor of Public Health (DrPH) from Universiti Putra Malaysia. We are grateful to the Director General of Health Malaysia for his permission to publish this article. 


\section{REFERENCES}

1. Ithnin A. Amirul M. Knowledge, Attitude and Practices (KAP) of Safety and Health among Students in School, Int J Environ Res Public Health 2016;13(1): 41-44.

2. Arokiasamy JT. Some Epidemiological Aspects and Economic Costs of Injuries in Malaysia, Asia Pac J Public Health 1994; 7(1): 16-20.

3. Norazmir MN, Noor Hasyimah MA, Siti Shafurah A, Siti Sabariah B, Ajau D, Hazali N Knowledge and practices on food safety among secondary school students in Johor Bahru, Johor, Malaysia. Pak J Nutr 2012; 11(2): 110115.

4. Pisaniello DL, Stewart SK, Jahan N, Pisaniello SL, Winefield $\mathrm{H}$, BraunackMayer A. The role of high schools in introductory occupational safety education - Teacher perspectives on effectiveness. Safety Science 2013; 55: 53-61.

5. Doumet MH. How Primary and Secondary Teachers Differ and Why it Matters. Education And Skills Today: Global Perspectives on Education and Skills 2018 [Blogspot] Retrieved from http: / / oecdeducationtoday.blogspot. com/

6. Manjunath C, Kumar NN. Oral health knowledge, attitude and Practices among school teachers in Kurnool Andhra Pradesh. Journal of Oral Health and Community Dentistry. 2013 ;7(1):17-24.

7. Sekhar V, Sivsankar P, Easwaran MA, Subitha L, Bharath N, Rajeswary K, Jeyalakshmi S. Knowledge, Attitude and Practice of School Teachers towards Oral Health in Pondicherry. J Clin Diagn Res. 2014; 8(8): ZC12- ZC15.

8. Ofovwe GE, Ofili AN. Knowledge, Attitude and Practice of School Health Programme among Head Teachers of Primary School in Egor LGA of Edo State. Ann Afr Med. 2007; 6(3): 99-103.

9. Al-Beiruti, N. Oral Health Behavior among a Sample of School Teachers, Physician and Nurses in the Syrian Arab Republic. East Mediterr Health J 1997; 3(2): 258-262.

10. Misnan MS, Mohammed AH, Dalib AR. Pembangunan budaya keselamatan di tempat kerja. 2011. Penerbit UTM, Skudai, Johor Bahru. ISBN 978-983-520800-3

11. Gimeno JB, Ibanez RM. The Education for Primary and Secondary School Teachers: An International Comparative Study. 1981. The United Nations Educational, Scientific and Cultural Organization (UNESCO) Press. Retrieved from http: / / unesdoc.unesco.org/images / 0 004/000455/045520eo.pdf 